\title{
Modeling the Total Allowable Area for Coastal Reclamation: A Case Study of Xiamen, China
}

Benrong Peng ${ }^{a^{*}}$, Chenchen Lin, Di Jin ${ }^{\mathrm{b}}$, Huanhuan Rao ${ }^{\mathrm{a}}$, Yuwu Jiang ${ }^{\mathrm{a}}$, Yan Liu ${ }^{\mathrm{c}}$

a Joint Key Laboratory of Coastal Study, Coastal and Ocean Management Institute Environmental Science Research Center Xiamen University, Xiamen, Fujian 361005, China

\author{
${ }^{\mathrm{b}}$ Marine Policy Center \\ Woods Hole Oceanographic Institution \\ Woods Hole, MA 02543, USA
}

${ }^{\mathrm{c}}$ China Institute for Marine Affairs, State Oceanic Administration, Beijing 100860, China

*Corresponding author. Email address:brpeng@xmu.edu.cn 


\title{
Modeling the Total Allowable Area for Coastal Reclamation: A Case Study of Xiamen, China
}

\begin{abstract}
This paper presents an analytical framework to estimate the Total Allowable Area for Coastal Reclamation (TAACR) to provide scientific support for the implementation of a coastal reclamation restriction mechanism. The logic of the framework is to maximize the net benefits of coastal reclamation subject to a set of constraints. Various benefits and costs, including the ecological and environmental costs of coastal reclamation, are systematically quantified in the framework. Model simulations are developed using data from Tongan Bay of Xiamen. The results suggest that the TAACR in Tongan Bay is $5.67 \mathrm{~km}^{2}$, and the area of the Bay should be maintained at least at $87.52 \mathrm{~km}^{2}$.

Keywords: Total allowable reclamation, Optimal reclamation area, Benefit and cost analysis, Xiamen
\end{abstract}

\section{Introduction}

Coastal areas have been the centers of human activity for millennia because of their remarkable biological productivity and high accessibility (WRI, 2001). About 40 percent of the world's population, half of the production and consumption activities are concentrated in the coastal zones which account for only $10 \%$ of all land area (Pernetta and Elder, 1993). The costal zones with high population density confront a common problem, the deficit of space. Coastal reclamation is the solution for almost all coastal societies to ease the pressure of land shortage. Large scale sea reclamation activities can be observed in island countries such as Japan, Korea, and Singapore, as well as non-island countries such as Holland, German, and United States (UNAOO, 2006). Although coastal reclamation can create useful space for agriculture, industry, 
and urban land area, it usually comes at a price of the environment (Li et al., 2008; Zhang et al., 2010). The conversion of sea to land permanently changes the natural characteristics of the ocean and coastal environment and damages considerably the marine ecosystems which human-kind depends on (Xia et al., 2007; Hoeksema, 2007; Airoldi and Beck, 2007; Halpern et al., 2008).

In China, about 13.4 million ha of tidal lands have been reclaimed for agriculture, salt-making, mariculture, and other industrial and urban development uses since the middle of the $20^{\text {th }}$ century (Fu et al., 2010). This has led to the losses of almost half of the country's coastal wetlands and 73 percent of the country's mangroves, which has, in turn, led to a decrease in shellfish production and a loss of general productivity in the reclaimed areas (SOA, 2003; PEMSEA, 2003)

The existing laws and regulations in China have not been effective in controlling coastal reclamation. Usage charge regime in Sea Area Use Management Law of PRC (SAUML) promulgated in 2001 provides the economic incentive to control coastal reclamation (Article 33). But the present usage charge standard for coastal reclamation is too low to curtail the activity level (Peng et.al. 2011). The central government's review and permitting regime for large scale sea area use project requires that projects with reclaimed sea area above 50 hectare must get the approval from the State Council (Article 18). To avoid the stringent review of a large scale project, developers often divide the whole project into several smaller projects. The reduction and exemption provisions of sea area use charge (article 35 and 36 of SAUML) further restrict the application of economic incentives to control large scale coastal reclamation projects implemented by the government.

Marine Environmental Protection Law of PRC (MEPL) implemented in 1982 (amended in 1999) requires that an environmental impact assessment (EIA) must be conducted for any new, reconstruction or expansion ocean/coastal construction project, including coastal reclamation projects (article 43 and 48). Unfortunately, the EIA typically focus on a single project and does not consider the cumulative environmental impacts of other related projects in the same area. As a result, the EIA requirement cannot effectively control excessive reclamation. 
Moreover, the majority of coastal reclamation projects are resulted from local government backed development programs. Even though the central government calls for strict restrictions on coastal reclamation, a large number of reclamation plans are still being put forward in coastal provinces. As a new national coastal development strategy unfurls, ${ }^{1}$ there will be a demand for an additional $5,780 \mathrm{~km}^{2}$ of sea area to be reclaimed by the year 2020 in China (Task Force of CCICED, 2010), which undoubtedly will exert severe impacts on the coastal environment. Thus, there is an urgent need to develop a new approach to control effectively coastal reclamation and to harmonize the demand for reclamation and the protection of marine and coastal ecosystems. One of the solution is to set up a coastal reclamation restriction mechanism, known as the "red-line system," similar to that in the nation's arable land protection policy (Task Force of CCICED, 2010).

The coastal reclamation red-line system involves the establishment of a critical minimum sea area in each specific bay, and the minimum area will be written into law. The estimation of the critical minimum sea area should consider fully the multiple benefits and costs associated with reclamation. The red-line system is expected to be more effective in controlling reclamation, since anyone, including the government, who tries to pass the line must change the law first, which is a difficult and lengthy process. To implement the system at a specific bay, it is essential to figure out the total allowable areas for coastal reclamation (TAACR) at that location. The main advantage of the TAACR approach described here over other command and control management alternatives lies in the fact that the development of TAACR is science-based and captures the tradeoffs between economic growth and environmental protection.

The remainder of the paper is organized as follows. Section 2 presents the analytical framework and models to estimate TAACR. Data sources, specific estimation procedures, and results are presented in Section 3. Limitations of the study are discussed in Section 4. Conclusions are included in Section 5.

\footnotetext{
${ }^{1}$ http://news.xinhuanet.com/local/2009-06/24/content_11573216.htm
} 


\section{Methods}

\subsection{Basic model}

The basic idea of estimating the TAACR is straightforward in theory. Reclaimed land can be used for food production, urban development, and attracting new investment, which contribute to various social benefits. Meanwhile, coastal reclamation involves a series of costs, including social and environmental costs. From the standpoint of the society, the objective of a social planner in charge of coastal reclamation is to maximize the net societal benefit by choosing an optimal set of location and scale for reclamation. The estimated optimal reclamation area with its localization is the TAACR.

The net benefit maximization problem is a static problem described by:

$$
\begin{aligned}
& \text { Max. } N B=\sum_{i=1}^{n}\left[p_{i} \times f\left(x_{i}\right)-c\left(x_{i}\right)\right]-\sum_{i=1}^{n} \sum_{k=1}^{m} C^{k}\left(x_{i}\right) \\
& \text { s.t. } \\
& h_{i}\left(x_{i}\right) \leq h_{i} \max
\end{aligned}
$$

where $N B$ is the net benefit of coastal reclamation; $i(=1,2,3, \ldots, n)$ is the reclamation location index; $p_{i}$ is for the price of products from the reclaimed land at the location $i$; $f\left(x_{i}\right)$ stands for the production function which is a function of the area of reclaimed land at location $i, x_{i} ; c\left(x_{i}\right)$ denotes the production cost function for reclaimed land at location $i ; k(=1,2,3, \ldots, m)$ is the index for reclamation cost components; $C^{k}\left(x_{i}\right)$ stands for the cost function for the $k^{\text {th }}$ component at location $i$; and function $h_{i}$ denotes the constraint for reclamation at location $i$, such as scale constraint and no net loss of key coastal ecosystems, which is a linear function in $x$.

For a solution to the problem, $x_{i}^{*}$ (a specific reclamation area at each location $i$ ), the necessary conditions for optimality are the Kuhn-Tucker conditions. It is assumed that the total reclamation costs are quasi-convex, all separate cost functions are convex, and the objective function is quasi-concave. The Hessian matrix to the Lagrangian is negative semi-definite, and a unique maximum exists. 
The necessary Kuhn-Tucker conditions are given in (3) - (6).

$$
\begin{aligned}
& p_{i} \times \frac{\partial f\left(x_{i}^{*}\right)}{\partial x_{i}}-\frac{\partial c\left(x_{i}^{*}\right)}{\partial x_{i}}-\sum_{k=1}^{m} \frac{\partial C^{k}\left(x_{i}^{*}\right)}{\partial x_{i}}-\lambda_{i} \frac{\partial h\left(x_{i}^{*}\right)}{\partial x_{i}}=0 \\
& h_{i}\left(x *_{i}\right) \leq h_{i} \max \\
& \lambda_{i} h_{i}\left(x_{i}^{*}\right)=0 \\
& \lambda_{i} \geq 0\left(=0 \text { if } h_{i}\left(x_{i}^{*}\right)<h_{i} \max \right)
\end{aligned}
$$

The condition in (3) ensures optimality, (4) is feasibility conditions, (5) is the complementary slackness condition, and (6) is a non-negativity condition. $\lambda_{i}$ is the Lagrangian multipliers, which represents shadow prices. The optimality condition (3) indicates that the socially optimal level of coastal reclamation $\left(x_{i}^{*}\right)$ should be set at the point where marginal social costs equal marginal social benefits.

\subsection{Revenue of coastal reclamation}

The revenue from coastal reclamation at a specific location $i$ is reflected in the term $\left[p_{i} \times f\left(x_{i}\right)-c\left(x_{i}\right)\right]$ in equation (1), which is the difference between the value of goods produced from the reclaimed land and the costs turning the reclaimed land into the goods. In natural resource economics (Hartwick, 1997), this difference is the rent or the price of reclaimed land. Considering that the reclaimed land accounts for a small portion of existing land supply and thus the addition of the reclaimed land will not affect the market price of existing coastal land, the marginal revenue of reclaimed land can be estimated using the market price of adjacent land.

As mentioned above, the reclaimed land can be used for different uses. The price of land for different use is different. Moreover, the price of land located in different place varies significantly. The price of reclaimed land at location $i$ can be calculated as the weighted average value according to the planned use pattern: 


$$
P_{i}=\sum_{j=1}^{j=J} P_{i j} \times s_{i j}
$$

where $j(=1,2,3, \ldots, J)$ is the index for the land use; $P_{i j}$ stands for the price of land in location $i$ for use $j$; $s$ is the weight.

\subsection{Cost of coastal reclamation}

The cost of costal reclamation can be grouped into four parts: (1) engineering cost, (2) ecosystem damages, (3) cost of siltation, and (4) reduction in environmental carrying capacity. Engineering cost is the cost of filling the sea area which can be estimated through field investigation or engineering analysis.

The coastal ecosystems provides various services to society, such as providing food and materials, storing and cycling nutrients, filtering pollutants from inland freshwater systems, protecting shorelines from erosion and storms, regulating global hydrology and climate, and accepting and assimilating waste. Coastal reclamation will destroy all these services in the reclaimed area and reduce the ability of adjacent ocean and coastal ecosystems to provide above services. The value of coastal ecosystem services must be assessed so that damages to the ecosystems resulting from reclamation can be estimated.

Coastal reclamation will change the hydrological condition and lower the tidal volume of the bay, which will lead to an increase in siltation in navigation channels. Dredging cost can be used to assess the cost of siltation. The reduction in the tidal volume also leads to a reduction in the capacity of coastal waterbody to absorb wastes. As a result, coastal communities must take measures to increase their waste treatment capacity. The increased treatment costs can be used to estimate the cost associated with the reduction in environmental carrying capacity.

\subsection{Annual value}

In China, prices of land reflect the present value of land use right in the period prescribed by law. The statutory maximum life of commercial and industrial use is 70 and 50 years, respectively. Other estimates, such as the costs of ecosystem damages, 
are often expressed in terms of annuity. In the study, we compare the benefits and costs associated with reclamation using the annual values.

Benefits (e.g., price of land) and costs in lump-sum payments are converted into average annual values using the formula below.

$$
A=S \frac{(1+r)^{n} r}{(1+r)^{n}-1}
$$

where $A$ is the annuity of benefits or costs; $S$ is the associated lump-sum values; $r$ is the discounted rate; and $n$ is the number of years.

Engineering costs of coastal reclamation $\left(C^{E N G}\right)$ incurred upfront typically lead to a stream of benefits into indefinite future. Thus, the annual value of engineering cost $C^{E N G A}$ is calculated as:

$$
C^{E N G A}=C^{E N G} \times r
$$

\section{The case study}

Located at the southeastern coast of China's Fujian Province, to the west of Taiwan Strait, Xiamen covers a land area of $1,565 \mathrm{~km}^{2}$ and a sea area of $340 \mathrm{~km}^{2}$ with a coastline of $234 \mathrm{~km}$. Xiamen's economic development and well-being depend heavily on its surrounding seas for natural resources, goods and services. As shown in Figure 1, the study area has a long history of coastal reclamation. A total of 128.72 $\mathrm{km}^{2}$ sea area has been reclaimed since the 1950s (Table 1). An estimate in 2006 indicated that the areas of West Sea and Tongan Bay had decreased 58\% and 27\%, respectively, due to the coastal reclamation (Zhang et al., 2008).

Large scale reclamation has led to the disappearance of $90 \%$ of the natural mangroves and the destruction and alteration of natural habitats of various living resources. Together with other human activities, coastal reclamation has resulted in the degradation of marine environmental quality, an increase in eutrophication and associated red tides, ${ }^{2}$ reductions in fisheries resources and other marine species, ${ }^{3}$ and

\footnotetext{
2 The number of red tide occurrences increased from 0 in the 1980s to 5 times in 2010 (Xiamen Ocean and
} 
siltation of navigation channels.

With the deterioration of environmental and resource conditions, the development in Xiamen is not sustainable. However, to cope with rapid economic development, population growth, and urbanization, a reclamation plan of $20 \mathrm{~km}^{2}$ has been proposed (Figure 2), in which the eight planned areas to be reclaimed in Tongan Bay (TA1 to TA8) represent a total of $15.22 \mathrm{~km}^{2}$ (16.33\% of the current bay area) (see Table 2). There is an urgent need for Xiamen to assess the optimal scale and location for coastal reclamation and to identify an effective approach to preserve the minimum sea area that can maintain the resilience and health of its marine ecosystems.

In this section, we describe an empirical estimation of TAACR in the Tongan Bay of Xiamen, whose area has decreased to $93.2 \mathrm{~km}^{2}$ from $127 \mathrm{~km}^{2}$ over the years due to coastal reclamation. We explain the procedures for compiling data and model computation, together with background information related to the benefit and cost functions of coastal reclamation. The 20 -year government bond rate $4.5 \%$ is taken as the social discount rate for our baseline calculation.

\subsection{Parameter estimation}

According to the plan, reclaimed land will be mainly used for commercial and industrial purposes. ${ }^{4}$ To establish the benefit function for the reclaimed land, we assemble the land price for commercial and industrial uses in areas adjacent to each of the planned reclamation locations (column 5 and 6 in Table 2). Using the shares for commercial and industrial uses (column 3 and 4 in Table 2) and equations (7) and (8), the weighted average prices for different planning reclamation areas are calculated (last column in Table 2). We use a linear benefit function for each reclaimed area $i$ in

\footnotetext{
Fisheries Bureau, Personal communication, 2012).

${ }^{3}$ Annual fishery catch decreased from 25 thousand ton in 1990 to 7.4 thousand ton in 2010 (Xiamen Statistics Bureau, 1991 and 2011).

${ }^{4}$ As shown in Table 1, the reclaimed land was mostly used for mariculture and salt making in the earlier years, and later converted to industrial and commercial uses because land values are significantly higher for these uses.
} 
the study: $B_{i}\left(x_{i}\right)=P_{i} x_{i}$.

The results of studies on reclamation projects in Xiamen indicate that the average fixed and operation costs of coastal reclamation are $600 \mathrm{yuan} / \mathrm{m}^{2}$ and $60 \mathrm{yuan} / \mathrm{m}^{2}$, respectively (TIO and $4^{\text {th }}$ NFRDI, 2002; $4^{\text {th }}$ NFRDI, 2002; PDRINBYR, 2003). Thus, the estimate of $660 \mathrm{yuan} / \mathrm{m}^{2}$ is used as the engineering cost in the study. The lump-sum cost is converted to an annual value of $29.7 \mathrm{yuan} / \mathrm{m}^{2}$ using equation (9). The engineering cost function, $C_{i}^{E N G A}\left(x_{i}\right)$ is: $C_{i}^{E N G A}\left(x_{i}\right)=29.7 x_{i}$.

The Coastal and Ocean Management Institute of Xiamen University (COMI, 2012) has developed estimates of the values associated with ecosystem services for each Xiamen's coastal areas (Table 3). Coastal reclamation will destroy all the services provided by these areas. Thus, the values of ecosystem services can be used as the costs of ecosystem damages due to reclamation. The costs functions of ecosystem damages, $C_{i}^{E D}\left(x_{i}\right)$ can be written as: $C_{i}^{E D}\left(x_{i}\right)=e_{i} x_{i}$, where $e_{i}$ is the value of ecosystem services listed in column 2 in Table 3.

Fujian Marine Institute and the State Key Laboratory of Marine Environmental Science at Xiamen University (2006) have developed models of hydrodynamics, sand and mud sediments, and water quality for the West seas and Tongan Bay. These models have been used to assess the impacts of various proposed reclamation schemes. In the present study, different reclamation scenarios are examined to evaluate the cumulative effects of reclamation at an increasing scale (column 2 in Table 4). The volume of siltation per year and tidal volume per period ${ }^{5}$ are list in columns 4 and 6 in Table 4.

According to the Xiamen Port Bureau, the average unit dredging cost is 29.7 yuan $/ \mathrm{m}^{3}$. Thus, the dredging costs associated with different reclamation scenarios can be calculated as the product of the unit cost and the volume of siltation (column 5 in Table 4). The value of environmental carrying capacity for different reclamation scenarios is estimated as (column 7 in Table 4):

\footnotetext{
${ }^{5}$ There are two tidal periods in Xiamen Sea area per day.
} 


$$
V=365 \times 2 \times \Delta c \times v \times c
$$

where $\Delta c$ is the difference in COD concentrations between inner and outer Tongan Bay $(\Delta c=0.02 \mathrm{mg} / \mathrm{L}, \mathrm{Xiamen} \mathrm{EPB}, 2006) ; v$ is the tidal volume; and $c$ is the unit cost of treatment of COD ( $c=4300$ yuan per ton, TIO, 1995).

Using the cost estimates in Table 4, we construct the marginal cost functions with respect to reclamation area $(x)$ using Ordinary Least Squares regressions, and the results are as follows: ${ }^{6}$

$$
\begin{array}{ll}
\frac{d C^{d c}}{d x}=0.0008 x+1.244 & \left(\mathrm{R}^{2}=0.95\right) \\
\frac{d C^{e c c}}{d x}=0.306 x+5.298 & \left(\mathrm{R}^{2}=0.99\right)
\end{array}
$$

Equations (11) and (12) are the marginal drudging cost function and the marginal treatment cost function, respectively.

\subsection{The optimal reclamation scheme}

The net benefit maximization problem was solved using the information from the previous sections and the GAMS software. The scale constraint for each location, $h_{i}$ max, in equation (4) is its planned area (column 2 in Table 2). ${ }^{7}$ The results show that the optimal reclamation area in Tongan Bay is $567.85 \mathrm{ha}^{2}\left(5.68 \mathrm{~km}^{2}\right)$ at a discount rate of $4.5 \%$ (see Table 5). This optimal area is $37.31 \%$ of the total planned reclamation area, suggesting that the proposed reclamation plan is economically inefficient from the stand point of the entire society. With the TAACR estimated at $5.68 \mathrm{~km}^{2}$, we argue that the area of Tongan Bay must be maintained at a minimum of $87.52 \mathrm{~km}^{2}$ so that the social well-being can be preserved.

The optimal location and scale of reclamation are shown in Table 5. The results indicate that there should be no reclamation at location TA8, and the optimal

\footnotetext{
${ }^{6}$ All parameters are statistically significant at $1 \%$ level.

7 The planned reclamation location and sizes were selected to avoid environmentally sensitive areas in the region.
} 
reclamation scales at location TA3 and TA5 are less than half of what are planned. ${ }^{8}$

We develop a sensitivity analysis with respect to discount rate using two alternative discount rates, $2 \%$ and $8 \%$, respectively. As shown in columns 4 and 5 in Table 5, under low discount rate, $2 \%$, the TAACR is zero. Even with high discount rate, $8 \%$, the optimal reclamation area is $789.42 \mathrm{ha}^{2}$, about half of the total planned area. The area of Tongan Bay must be maintained at a minimum of $85.31 \mathrm{~km}^{2}$. Thus, the results clearly indicate that our estimation is robust with respect to discount rate.

\section{Discussion}

Although the analytical framework developed in the study presents an effective way to assess the tradeoffs between development and conservation, the framework has several limitations. First, several ecosystem damage costs are modeled as linear functions in the study. However, many of these costs are nonlinear due to nonlinear interactions in the natural systems (Barbier et al. 2008). In addition, we do not have a good understanding of the ecological thresholds in the study area. When a system crosses a threshold, a very small change in economic activity can have enormous impacts and result in irreversible loss of critical natural capital (Farley, 2012).

Finally, the natural and socioeconomic systems are highly complex and dynamic. Our static model cannot capture the full effects of the dynamic interactions in the coastal systems. Sustainable development is an evolutionary process, and sustainability is not a static objective. Thus, an adaptive management system must be in place to cope with various uncertainties (Rammel et al. 2007). In fact, our estimation of the TAACR for Xiamen should not be viewed as static, and it should be reevaluated periodically so that new knowledge can be incorporated into the analysis to guide future reclamation or restoration plans.

\section{Conclusions}

While creating useful land for agriculture, industries, and urban development,

\footnotetext{
${ }^{8}$ Downsizing the reclamation scale at these sites will involve reassessment and re-planning at each site, which is beyond the scope of this study.
} 
coastal reclamation permanently changes the natural characteristics of the ocean and coastal environment and causes considerable damages to the marine ecosystems. Policymakers must be careful about the tradeoffs between the short-term interest to provide additional land and the long-term interest to ensure the sustainable use of the marine and coastal ecosystems. By assessing the optimal scale and location for reclamation, we may be able to meet the current demand for land to facilitate economic development while maintaining the health and resilience of the coastal ecosystems. The analytical framework and models developed in the study covers multiple benefits as well as cost components associated with coastal reclamation. The inclusion of multiple uses and environmental and ecological effects in the analysis is vital, since it is essential to consider the welfare from the stand point of the whole society. Our empirical estimation captures both internal and external effects.

Our results indicate that the optimal reclamation scale is $5.68 \mathrm{~km}^{2}$ in Tongan Bay, Xiamen with a discount rate of $4.5 \%$. Even with high discount rate, $8 \%$, the optimal size of reclamation is about half of what is planned. If we focus more on the long-term ecological benefits by using a lower discount rate of $2 \%$, the optimal reclamation area should be zero. In order to maintain the ability of the coastal ecosystems to provide various services to society, Xiamen should reexamine and reformulate its plan for coastal reclamation so that the area of Tongan Bay is kept at a minimum of $87.52 \mathrm{~km}^{2}$.

It must be stressed that the estimated optimal reclamation area should be viewed as the maximum, because some costs, such as the damages to adjacent coastal ecosystems and the increased treatment costs for other pollutants such as nutrients resulted from the reduction in environmental carrying capacity, are not included in the current assessment for lack of data.

Although this study examines a case in Xiamen, the general framework presented here is transferable to other locations and can be used to examine reclamation proposals at different scales. Finally, as noted, the estimated Total Allowable Area for Coastal Reclamation (TAACR) must be written into law as part of the red-line system to ensure an effective control of coastal reclamation. 


\section{Acknowledgements}

The study was funded by the National Oceanic Public Welfare Projects (No.

201105006) and the Fujian Natural Science Foundation (No. 2010J01360) 


\section{References}

$4^{\text {th }}$ Institute of Navigational Engineering Exploration and Design, Ministry of Communication $\left(4^{\text {th }}\right.$ INEED), 2002. Feasibility research report of Xiangyu Free Trade Zone (second phase) Project. Xiamen, China.

Airoldi, L., Beck, M.W., 2007. Loss, status and trends for coastal marine habitats of Europe. Oceanography and Marine Biology, 45, 345-405.

Barbier, E.B., Koch, E.W., Silliman, B.R., Hacker, S.D., Wolanski, E., Primavera, J., Granek, E.F., Polasky, S., Aswani, S., Cramer, L.A., Stoms, D.M., Kennedy, C.J., Bael, D., Kappel, C.V., Perillo, J.M.E., Reed, D.J., 2008. Coastal ecosystem-based management with nonlinear ecological functions and values. Science. 319, 321-323.

Coastal and Ocean Management Institute, Xiamen University (COMI), 2012. The compensation standard of ecological damage in sea area use and implementation scheme in Xiamen. Xiamen, China.

Farley, J., 2012. Ecosystem services: the economics debate. Ecosystem Services. 1, 40-49.

Fu, Y.B., Cao, K., Wang, F., Zhang, F.S., 2010. Preliminary study of the methods used to evaluate the potential impacts of coastal reclamation. Ocean Development and Management. 27(1): 27-30.

Fujian Marine Institute and the State Key Laboratory of Marine Environmental Science (Xiamen University), 2006. Study on the total quantity control of sea reclamation in West Sea and Tongan Bay of Xiamen. Xiamen, China.

GEF/UNDP/IMO Regional Programme on Partnerships in Environmental Management for the Seas of East Asia (PEMSEA), 2003. The Development of National Coastal and Marine Policies in the People's Republic of China: A Case Study. Quezon City, Philippines.

Halpern, B.S., Walbridge, S., Selkoe, K.A., Kappel, C.V. , Micheli, F., D'Agrosa, C., Bruno, J.F., Casey, K.S., Ebert, C., Fox, H.E., Fujita, R., Heinemann, D., Lenihan, H.S., Madin, E..P., Perry, M.T., Selig, E.R., Spalding, M., Steneck, R., Watson, R., 2008. A global map of human impact on marine ecosystems. Science. 319, 948-952.

Hartwick, J.N., Olewiler, N.D., 1997. The Economics Of Natural Resource Use, $2^{\text {nd }}$ ed. Addison-Wesley, New York.

Hoeksema R.J., 2007. Three stages in the history of land reclamation in the Netherlands. Irrigation and Drainage, 56 (s1), 113-126.

Li, T.H, Han, P., Zhao, Z.Z., 2008. Impact analysis of coastal engineering projects on mangrove wetland area change with remote sensing. China Ocean Engineering. 22 (2), 347-358. 
Panning and Design Research Institute of Navigational Bureau of Yangtze River (PDRINBYR), 2003. Feasibility research report of removing silt and shoreline treatment project in seas around Xiamen Bridge. Xiamen, China.

Peng, B., Hong, H., Chen, W., 2011. Integrating ecological damages into the user charge for land reclamation: a case study of Xiamen, China. Stochastic Environmental Research and Risk Assessment, 25, 341-351.

Pernetta J., Elder D., 1993. Cross-Sectoral, Integrated Coastal Area Planning (CICAP): Guidelines And Principle For Coastal Area Development. IUCN, Gland, Switzerland.

Rammel, C., Stagl, S., Wilfing, H., 2007. Managing complex adaptive systems - a co-evolutionary perspective on natural resource management. Ecological Economics. 63(1), 9-21.

State Oceanic Administration (SOA), 2003. Bulletin of China's Marine Environmental Quality 2002. Bejing, China. Available at http://www.soa.gov.cn/soa/hygbml/hjgb/two/webinfo/2007/10/1271382648464061.ht m. Accessed 3 Feb 2012.

Task Force of the China Council for International Cooperation on Environment and Development (CCICED), 2012. Ecosystem Issues and Policy Options addressing the Sustainable Development of China's Ocean and Coast. China Environmental Science Press. Beijing, China.

Third Institute of Oceanography, State Oceanic Administration (TIO), 1995. Study on the Environmental Carrying Capacity of Xiamen Seas. Xiamen, China.

Third Institute of Oceanography, State Oceanic Administration (TIO) and $4^{\text {th }}$ Institute of Navigational Engineering Exploration and Design, Ministry of Communication (4th INEED), 2002. Feasibility Study on the Treatment Project Of Sea Areas and Tide Flats around Xiamen Bridge. Xiamen, China.

United Nations Atlas of the Oceans (UNAOO), 2006 Land Reclamation by the Coast. Available http://www.oceansatlas.org/servlet/CDSServlet?status=ND0xODAwOCY2PWVuJjM zPSomMzc9a29z. Accessed 4 Feb 2012.

World Resources Institute (WRI), 2001. Pilot Analysis of Globe Ecosystems: Coastal Ecosystems. WRI Publication, Washington, DC.

Xia, Z., Lei, Y., Chen, Y., 2007. Dynamics of coastal land use patterns of inner Lingdingyang Bay in the Zhujiang river estuary. Chinese Geographical Science. 17(3), 222-228.

Xiamen Environmental Protection Bureau (EPB), 2007. Xiamen Environmental State Report 2006. Xiamen, China.

Xiamen Statistics Bureau, 1991 and 2011. Yearbook of Xiamen Special Economic Zone. China Statistics Press, Beijing. 
Zhang, L.P, Chen, W.Q, Fang, Q.H, 2008. Retrospective Assessment of Environmental Impact of Reclamation Planning in Bays of Fujian Province. Science Press, Beijing, China.

Zhang, Q., Xu, C.Y., Chen Y.D., 2010. Wavelet-based characterization of water level behaviors in the Pearl River estuary, China. Stochastic Environmental Research and Risk Assessment, 24(1), 81-92. 
Table 1. Historical coastal reclamation and land uses

\begin{tabular}{|c|c|c|c|}
\hline Year & $\begin{array}{c}\text { Reclamation } \\
\text { area }\left(\mathrm{hm}^{2}\right)\end{array}$ & Share $(\%)$ & Uses \\
\hline 1950s-1960s & 5504 & 42.76 & \multirow{2}{*}{$\begin{array}{l}\text { Originally, the reclaimed areas were mainly } \\
\text { used for mariculture and salt making. But } \\
\text { these areas have switched to urban and } \\
\text { industrial uses. }\end{array}$} \\
\hline 1970s & 2907 & 22.59 & \\
\hline 1980s & 297 & 2.31 & \multirow{3}{*}{$\begin{array}{l}\text { Industrial zones, urban development, and } \\
\text { infrastructure (road, airport and dock, etc.) }\end{array}$} \\
\hline 1990s & 983 & 7.64 & \\
\hline $2000 \mathrm{~s}$ & 3180 & 24.71 & \\
\hline Total & 12872 & 100.00 & \\
\hline
\end{tabular}

Data source: Xiamen Ocean and Fisheries Bureau (Personal communication, 2012). 
Table 2. Revenue from planned reclamation areas

\begin{tabular}{|c|c|c|c|c|c|c|}
\hline \multirow{2}{*}{ Location } & Area $^{1}$ & \multicolumn{2}{|c|}{ Share of different uses } & \multicolumn{2}{|c|}{ Price of land ${ }^{3}\left(\mathrm{yuan} / \mathrm{m}^{2}\right)$} & \multirow{2}{*}{$\begin{array}{c}\text { Weighted average } \\
\text { price }\left(P_{i}\right)\left(\mathrm{yuan} / \mathrm{m}^{2}\right)\end{array}$} \\
\cline { 3 - 6 } & $\left(\mathrm{hm}{ }^{2}\right)$ & Commercial & Industrial & Commercial & Industrial & I46.69 \\
\hline TA1 & 16 & 0.8 & 0.2 & 3700 & 700 & 70.19 \\
\hline TA2 & 115 & 0.25 & 0.75 & 3700 & 700 & 70.19 \\
\hline TA3 & 213 & 0.25 & 0.75 & 3700 & 700 & 80.92 \\
\hline TA4 & 59 & 0.55 & 0.45 & 2900 & 250 & 74.59 \\
\hline TA5 & 429 & 0.55 & 0.45 & 2700 & 200 & 95.85 \\
\hline TA6 & 84 & 0.8 & 0.2 & 2500 & 150 & 90.33 \\
\hline TA7 & 161 & 0.75 & 0.25 & 2500 & 150 & 35.17 \\
\hline TA8 & 445 & 0.25 & 0.75 & 2500 & 150 & \\
\hline
\end{tabular}

Data sources: ${ }^{1,2}$ Xiamen Development and Reform Commission and Xiamen Ocean and Fisheries Bureau.

${ }^{3}$ Xiamen Land and Real Estate Bureau and field survey. 
Table 3. Value of ecosystem services of planned reclamation area and engineering cost

\begin{tabular}{|c|c|c|c|}
\hline \multirow{2}{*}{ Location } & $\begin{array}{c}\text { Value of ecosystem services } \\
\left(e_{i}\right)\left(\mathrm{yuan} / \mathrm{m}^{2}\right)\end{array}$ & \multicolumn{2}{|c|}{ Engineering cost $\left(\mathrm{yuan} / \mathrm{m}^{2}\right)$} \\
\cline { 2 - 2 } & 9.13 & $\begin{array}{c}\text { Present value } \\
\left(C^{E N G}\right)\end{array}$ & $\begin{array}{c}\text { Annual value } \\
\left(C^{E N G A}\right)\end{array}$ \\
\hline TA1 & 9.53 & & \\
\hline TA2 & 9.53 & \multirow{2}{*}{600} & \multirow{2}{*}{29.7} \\
\hline TA3 & 9.16 & & \\
\hline TA4 & 9.16 & & \\
\hline TA5 & 9.16 & & \\
\hline TA6 & 9.16 & & \\
\hline TA7 & 9.16 & & \\
\hline TA8 & &
\end{tabular}

Data source: COMI, 2012. 
Table 4. Dredging cost and value of carrying capacity of different reclamation scenarios

\begin{tabular}{|c|c|c|c|c|c|c|}
\hline Scenarios & Description & $\begin{array}{l}\text { Area } \\
\left(\mathrm{hm}^{2}\right)\end{array}$ & $\begin{array}{l}\text { Siltation } \\
\left(\mathrm{m}^{3}\right)\end{array}$ & $\begin{array}{c}\text { Dredging cost } \\
\left(10^{4} \text { yuan }\right)\end{array}$ & $\begin{array}{l}\text { Tidal volume } \\
\qquad\left(10^{6} \mathrm{~m}^{3}\right)\end{array}$ & $\begin{array}{c}\text { Value of } \\
\text { environmental } \\
\text { carrying capacity } \\
\left(10^{4} \text { yuan }\right)\end{array}$ \\
\hline 1 & No reclamation & 0 & 724399 & 2151.47 & 713.20 & 4477.47 \\
\hline 2 & TA1 & 16 & 724819 & 2152.71 & 711.62 & 4467.56 \\
\hline 3 & $\mathrm{TA} 1+\mathrm{TA} 2$ & 131 & 725266 & 2154.04 & 705.48 & 4429.00 \\
\hline 4 & TA1+TA2+TA3 & 344 & 725729 & 2155.42 & 693.91 & 4356.35 \\
\hline 5 & $\begin{array}{c}\mathrm{TA} 1+\mathrm{TA} 2+\mathrm{TA} 3 \\
+\mathrm{TA} 8\end{array}$ & 789 & 726262 & 2157.00 & 671.19 & 4213.71 \\
\hline 6 & $\begin{array}{c}\text { TA1+TA2+TA3 } \\
\text { +TA8+TA7 }\end{array}$ & 950 & 726743 & 2158.43 & 662.78 & 4160.95 \\
\hline 7 & $\begin{array}{c}\text { TA1+TA2+TA3 } \\
+ \text { TA8+TA7 } \\
\text { +TA4 }\end{array}$ & 1009 & 727171 & 2159.70 & 658.99 & 4137.11 \\
\hline 8 & $\begin{array}{c}\text { TA1+TA2+TA3 } \\
\text { +TA8+TA7 } \\
\text { +TA4+TA5 }\end{array}$ & 1438 & 727696 & 2161.26 & 637.41 & 4001.68 \\
\hline 9 & $\begin{array}{c}\text { TA1+TA2+TA3 } \\
+ \text { TA8+TA7+A4 } \\
\text { +TA5+TA6 }\end{array}$ & 1522 & 728131 & 2162.55 & 632.18 & 3968.84 \\
\hline
\end{tabular}

Data source: Fujian marine institute and the State Key Laboratory of Marine Environmental Science (Xiamen University), 2006. 
Table 5. Estimation results and sensitive analysis

\begin{tabular}{|c|c|c|c|c|}
\hline \multirow{2}{*}{ Location } & \multirow{2}{*}{$\begin{array}{c}\text { Planned area } \\
\left(\mathrm{hm}^{2}\right)\end{array}$} & \multicolumn{3}{|c|}{ Optimal reclamation area $\left(\mathrm{hm}^{2}\right)$} \\
\cline { 3 - 5 } & & $4.50 \%$ & $8 \%$ & $2 \%$ \\
\hline TA1 & 16 & 16.00 & 16.00 & 0.00 \\
\hline TA2 & 115 & 81.22 & 115.00 & 0.00 \\
\hline TA3 & 213 & 81.22 & 160.90 & 0.00 \\
\hline TA4 & 59 & 59.00 & 59.00 & 0.00 \\
\hline TA5 & 429 & 97.01 & 193.52 & 0.00 \\
\hline TA6 & 84 & 84.00 & 84.00 & 0.00 \\
\hline TA7 & 161 & 149.40 & 161.00 & 0.00 \\
\hline TA8 & 445 & 0.00 & 0.00 & 0.00 \\
\hline Total & 1522 & 567.85 & 789.42 & 0.00 \\
\hline
\end{tabular}




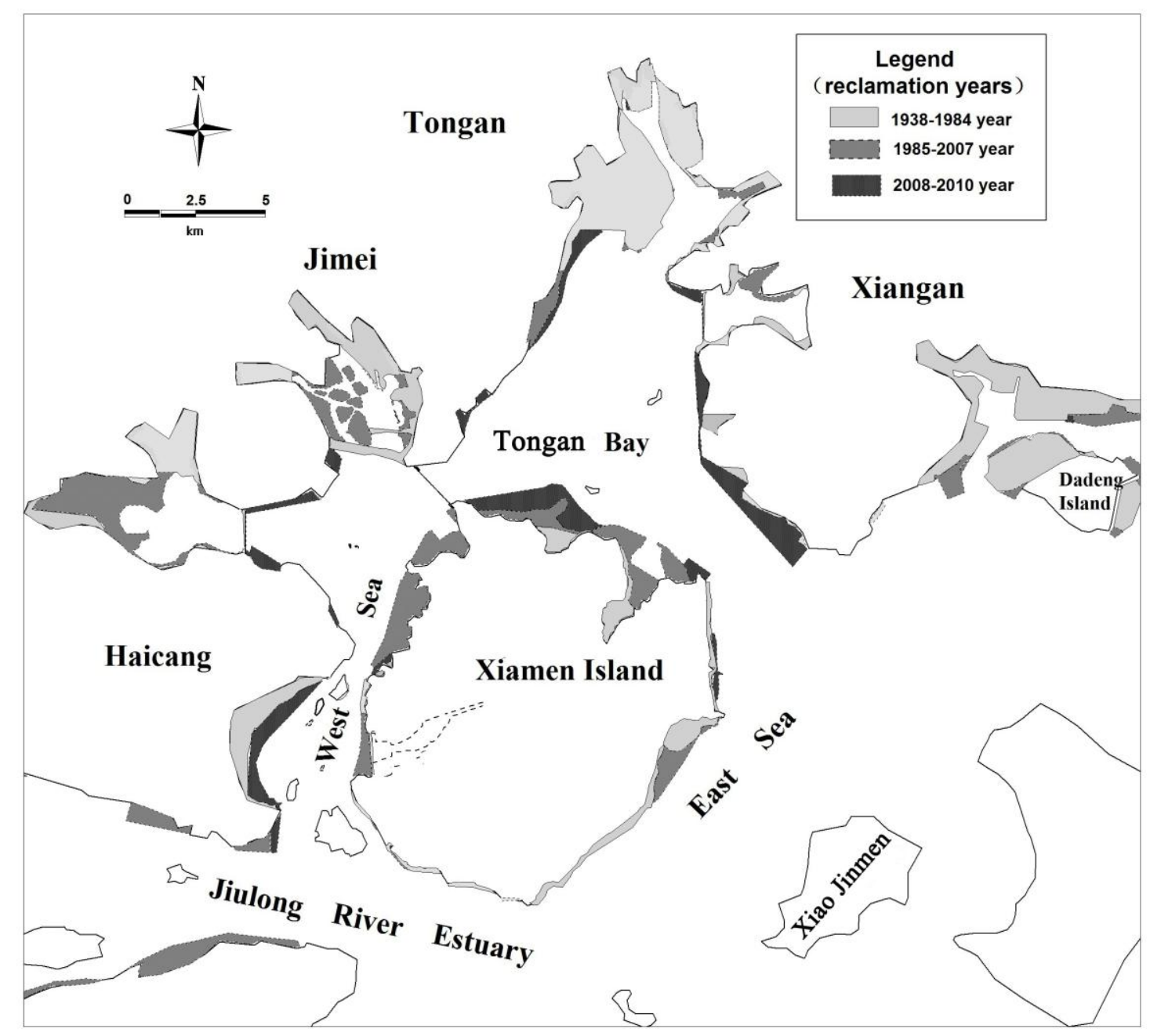

Figure 1. Historical development of coastal reclamation in Xiamen 


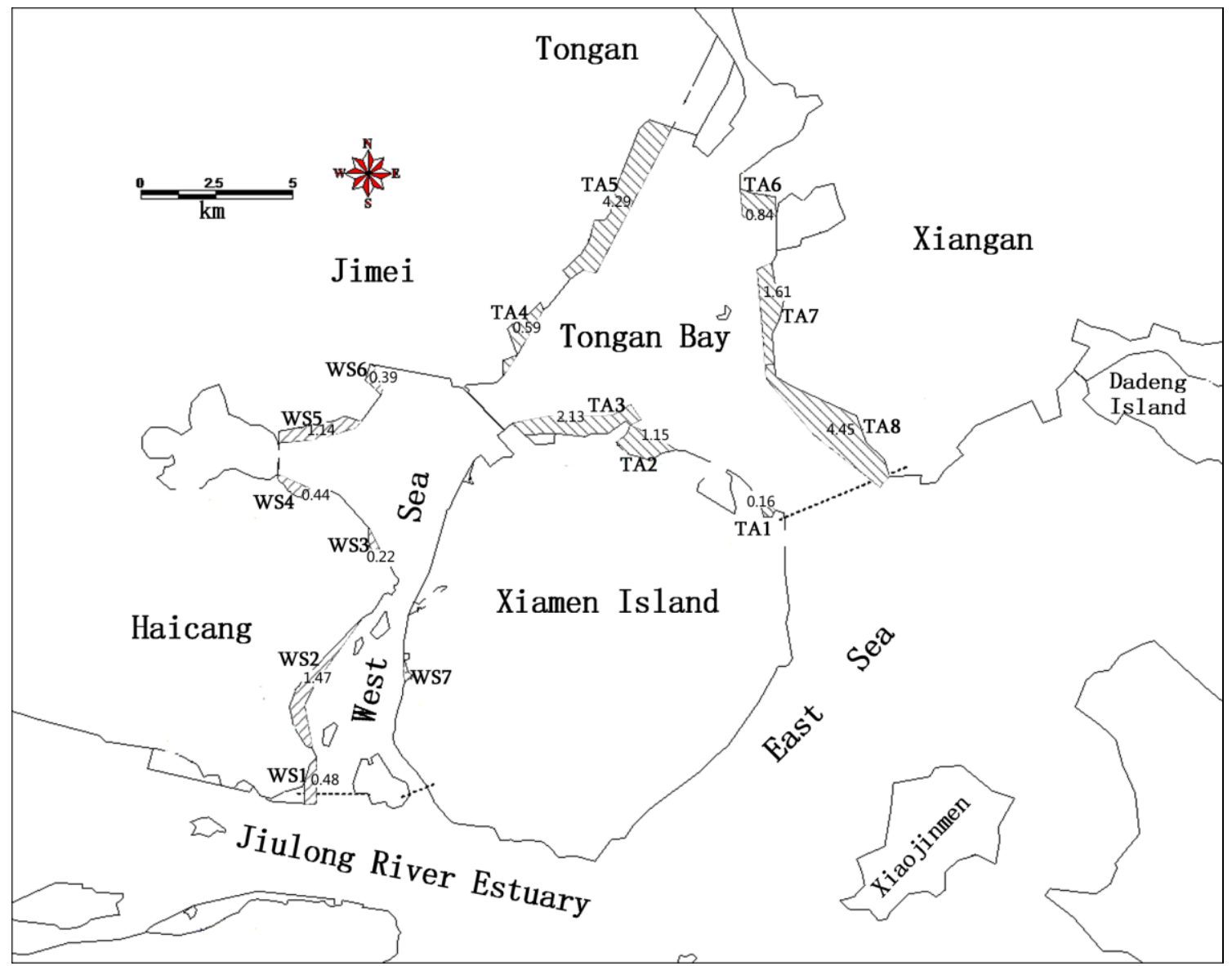

Figure 2. Location and area of planned reclamation（shadow areas are the planned reclamation sites) 